\title{
Nanofibrous alumina structures fabricated using high-yield alternating current electrospinning
}

Andrei Stanishevsky $^{1 *}$, W. Anthony Brayer ${ }^{1}$, Pavel Pokorny ${ }^{2}$, Thomáš Kalous ${ }^{2}$, David Lukáš ${ }^{2}$

${ }^{1}$ Department of Physics, University of Alabama at Birmingham, 1300 University Boulevard, Birmingham, AL 35294, USA

${ }^{2}$ Faculty of Textile Engineering, Technical University of Liberec, Studentska 2, Liberec 1, 461 17, Czech Republic

*Corresponding author. Email: astan@uab.edu

\begin{abstract}
Nanofibrous alumina $\left(\mathrm{Al}_{2} \mathrm{O}_{3}\right)$ structures were fabricated from the precursor aluminum nitrate/polyvinylpyrrolidone (PVP) nanofibers prepared using a free-surface alternating current (AC) electrospinning method. Precursor nanofibers were generated at rates up to $6.4 \mathrm{~g} / \mathrm{h}$ and collected as $100-300 \mu \mathrm{m}$ thick sheets suitable for direct conversion into the nanofibrous alumina structures. The effects of process conditions and annealing temperature on the nanofiber diameter, morphology, shrinking behavior and crystalline phase formation were investigated by Scanning Electron Microscopy (SEM), Fourier Transform Infrared (FTIR) spectroscopy, and Xray diffraction (XRD). Textural properties of $\mathrm{Al}_{2} \mathrm{O}_{3}$ fibrous sheets composed of micro-/mesoporous nanocrystalline $\gamma$-alumina nanofibers with $260 \pm 90 \mathrm{~nm}$ diameters after the calcination at temperatures in the range from $700{ }^{\circ} \mathrm{C}$ to $1000{ }^{\circ} \mathrm{C}$ were determined from $\mathrm{N}_{2}$ adsorption/desorption isotherms. Preliminary air permeability and apparent air flow resistance
\end{abstract}


studies of single sheet and multilayer nanofibrous alumina membranes were performed and compared with other porous alumina membrane structures for the evaluation of their possible usage in gas filtration, separation, and other applications.

\section{Introduction}

Ceramic structures with various levels of micro- to macro-porosity attract much attention due to a possibility to attain favorable combinations of mechanical, chemical, textural, and transport properties important for numerous applications in gas and liquid separation and filtration, biotechnology and pharmaceutical, food processing, environmental management, and catalytic processes [1-5].

Ceramic micro- and nanofibers are increasingly studied as a material suitable for the fabrication of porous ceramic structures for demanding applications [6-11]. Most of the nanofibrous ceramic materials are currently produced from precursor fibers made by electrospinning methods [12-15] that can provide a high level of control of the fiber dimensions, shape, structure and composition. Alumina $\left(\mathrm{Al}_{2} \mathrm{O}_{3}\right)$-based nanofibers have been of considerable interest due to their mechanical strength, chemical and thermal properties [16,17], and a possibility of the fabrication of stable self-supported fibrous membranes [18]. Alumina nanofibers are derived mainly from the precursor fibers prepared using the capillary needle DCelectrospinning [19-21] from various precursor solutions based on a metal salt and polymer [2226]. Usually, the annealing of electrospun precursor fibers at temperatures between $700{ }^{\circ} \mathrm{C}$ and $1400{ }^{\circ} \mathrm{C}$ results in micro-/mesoporous nanocrystalline alumina nanofibers with diameters in the range from 100 to $500 \mathrm{~nm}$, specific surface area from 3.0 to $260 \mathrm{~m}^{2} / \mathrm{g}$, and $\gamma-$ or $\alpha-\mathrm{Al}_{2} \mathrm{O}_{3}$ structure depending on the temperature. For example, Wang et al [27] prepared mesoporous $\gamma$ - 
alumina fibers with diameters $130-200 \mathrm{~nm}$ and BET surface area up to $264.1 \mathrm{~m}^{2} / \mathrm{g}$ after calcination at $700{ }^{\circ} \mathrm{C}$. They found that the mesopores disappear and a significant grain growth of $\alpha$-alumina phase occurs after calcination of these fibers at $1100{ }^{\circ} \mathrm{C}$. Kim et al [28] found that 260-350 nm alumina obtained from an aluminum isopropoxide/polyvinylpyrrolidone (PVP) precursor fibers exhibit the surface areas $178 \mathrm{~m}^{2} / \mathrm{g}$ and $43 \mathrm{~m}^{2} / \mathrm{g}$ after calcination at 800 and 1200 ${ }^{\circ} \mathrm{C}$, respectively. Similarly, Mahapatra et al [29] determined $40 \mathrm{~m}^{2} / \mathrm{g}$ surface area in 100-500 nm diameter $\alpha$-alumina fibers derived from the aluminum acetate/PVP precursor. On contrary, Saunders et al [30] found BET surface areas of $10.1 \mathrm{~m}^{2} / \mathrm{g}$ in $90-175 \mathrm{~nm} \gamma$-alumina fibers and 2.7 $\mathrm{m}^{2} / \mathrm{g}$ in $150-500 \mathrm{~nm}$ diameter corundum fibers prepared using the commercialized electrospinning processes.

Published results suggest that the composition and processing history of the precursor fibers play important roles in determining the diameter, microarchitecture and textural properties of calcined alumina nanofibers [31-34]. Strong reduction (1.5-3 times) of the precursor fiber diameter occurs due to the removal of polymer matrix and fiber structure densification during the annealing. This translates into the corresponding volume shrinkage of the precursor nanofiber mass or layer that may impact the development of extended self-supported nanofibrous ceramic structures. Currently, the data on such structures are limited.

In this work, extended nanofibrous alumina sheets with 100-300 $\mu \mathrm{m}$ thickness were fabricated from the precursor fibers prepared by an uncommon alternating current (AC) electrospinning method. This method is characterized by significantly reduced fiber jet instability and residual fiber charge $[35,36]$ as well as much higher fiber collection rates per unit area when compared to DC-electrospinning. Free-surface AC-electrospinning has been successfully utilized with several polymer fiber systems [37,38], but there were no studies of inorganic fibers 
prepared with the help of this method. The shrinking behavior of AC-electrospun precursor fibers and fibrous structures during the annealing was investigated in present experiments to explore the possibility of direct fabrication of self-supported porous nanofibrous ceramic structures. The work has also been focused on the characterization of nanofiber structure, and on textural properties of nanofibrous alumina sheets as well as on the preliminary evaluation of their air flow permeability.

\section{Experiment}

Aluminum nitrate nonahydrate $\left(\mathrm{Al}\left(\mathrm{NO}_{3}\right)_{3} \cdot 9 \mathrm{H}_{2} \mathrm{O}\right.$, Sigma Aldrich) and polyvinylpyrrolidone (PVP, $\quad \mathrm{M}_{\mathrm{w}}=1,300,000$, Sigma Aldrich) were used to prepare a precursor solution for electrospinning. The salt and polymer were dissolved in DI water and ethanol, respectively, and the solutions were mixed to obtain the salt-to-polymer ratios in a range from $0.5: 1.0$ to $2.0: 1.0$ in a base precursor with $10 \mathrm{w} \%$ of polymer. The base precursor was then diluted with either ethanol or water to vary the concentration and solvent composition. The precursors were stirred for up to $24 \mathrm{~h}$ using a magnetic stirrer and stored at normal laboratory conditions.

Viscosity of $\mathrm{Al}\left(\mathrm{NO}_{3}\right)_{3} / \mathrm{PVP}$ precursor solutions was determined using a HAAKE RotoVisco 1 from Thermo Scientific paired with Rheowin 4 Job and Data Manager Software. The RotoVisco was programmed to calibrate the zero point before each sample test. Once calibrated a drop of the solution was placed on the RotoVisco platform, and the viscosity values were recorded over a 120 -second time period at $1000 \mathrm{rpm}$. The viscosity graphs and recorded values were stored within the Rheowin 4 Data Manager and could be exported for further analysis. 
Electrical conductivity was measured using the WTW inoLab pH/Cond 720 instrument. The meter was calibrated according to the WTW inoLab 720 instruction manual. The AutoRead function was used to obtain at least 5 stabilized values for each sample.

Electrospinning of $\mathrm{Al}\left(\mathrm{NO}_{3}\right)_{3} / \mathrm{PVP}$ precursor nanofibers was carried out using two similar alternating current systems capable of producing AC-voltages up to $40 \mathrm{kV}$ rms and operated either at $60 \mathrm{~Hz}$ or $50 \mathrm{~Hz}[37,38]$. Initial observation of the precursor's spinnability was done by placing a small amount of precursor solution on circular electrodes with different diameters (6$25 \mathrm{~mm})$ and applying AC-voltage (15-40 kV rms). The formation of a stable flow of fibers served as major criterion for the selection of the precursor for further experiments. All stages of the fiber generation were recorded at $2000 \mathrm{fps}$ using an Olympus i-speed series camera as well as other photo- and video-recording equipment. Spinnable precursor solutions were loaded in an electrically insulated line equipped with a pump, and delivered through the base of electrode to its surface. Generated fibers were collected either on a flat sheet of paper, plastic mesh, or rotating plastic cylinder. A grounded collector was not used.

As prepared $\mathrm{Al}\left(\mathrm{NO}_{3}\right)_{3} / \mathrm{PVP}$ precursor nanofibers were normally removed from the support in a form of fibrous sheets with a thickness in a range from 100 to $300 \mu \mathrm{m}$ and dried in an oven at $80-120^{\circ} \mathrm{C}$ to eliminate the residual solvent and stabilize the material. Fibrous sheets were cut in pieces (typically $75 \times 25 \mathrm{~mm}$ ) and assembled into the up to 10 -sheet constructs. Some single and multi-sheet constructs were compressed for $300 \mathrm{~s}$ at up to $100 \mathrm{kPa}$ pressure applied normal to their surface and then placed between two 1-mm thin quartz plates to maintain their shape during the thermal processing. Next, the precursor nanofibers and fibrous sheets were calcined in air at temperatures ranging from $500{ }^{\circ} \mathrm{C}$ to $1000{ }^{\circ} \mathrm{C}$ for 2 hours using a programmable furnace (Isotemp from Fisher Scientific, heating rate $5{ }^{\circ} \mathrm{C} / \mathrm{min}$ ). 
Crystalline phase composition of the formed alumina nanofibers was determined using a Philips X'pert MPD thin-film X-ray diffractometer with a $\mathrm{Cu}$ Ka tube (wavelength $0.15406 \mathrm{~nm}$ ) operating at $45 \mathrm{kV}$ and $40 \mathrm{~mA}$. The detector was scanned between $20^{\circ}$ and $75^{\circ}$, with a constant take off angle of $5^{\circ}$. The experimental diffraction patterns were compared with the ICDD powder diffraction file (PDF) database [39]. The size of $\mathrm{Al}_{2} \mathrm{O}_{3}$ crystallites was estimated using Scherrer equation [40].

FTIR spectra (Vertex 70 spectrometer, Bruker Optics) were acquired in transmission mode from the nanofiber sheets positioned at the focal point of the IR beam path. In all cases, the FTIR spectra represented an average of 32 scans recorded with a resolution of $2 \mathrm{~cm}^{-1}$ for each sample.

The size, shape, and surface morphology of the precursor and alumina nanofibers were investigated by field-emission scanning electron microscopy (FE-SEM, FEI Quanta 650). SEM imaging was done in secondary electron mode, with an accelerating voltage of $15 \mathrm{kV}$, electron probe current $2 \mu \mathrm{A}$, and a chamber pressure of $1 \times 10^{-4} \mathrm{~Pa}$.

Textural properties of alumina nanofibers were determined using the Micromeritics ${ }^{\circledR}$ ASAP 2020 automatic physisorption analyzer. The Brunauer, Emmett, Teller (BET) surface area was calculated from isothermal adsorption of $\mathrm{N}_{2}$ at $77 \mathrm{~K}$. Barrett-Joyner-Halenda (BJH) analysis was used for pore volume and pore size distribution, and microporosity information was inferred through the t-plot analysis.

Fibrous alumina sheets calcined at different temperatures were also evaluated using a custom membrane capillary flow test cell similar to those described in $[41,42]$. Air permeability (in $\mathrm{m}^{2}$ ) and apparent air flow resistance (in $\mathrm{m}^{-1}$ ) of nanofibrous alumina sheets were determined according to Darcy's law [43] as $k_{D}=\mu h Q /(A \Delta P)$ and $R_{D}=h / k_{D}$, respectively, where $h$ is the membrane (sheet) thickness in meters, $Q$ is the air flow rate in $\mathrm{m}^{3} / \mathrm{s}, A$ is the area in $\mathrm{m}^{2}, \mu$ is the 
viscosity $\left(1.78510^{-5} \mathrm{~Pa} \cdot \mathrm{s}\right.$ for $\mathrm{N}_{2}$ at $\left.25^{\circ} \mathrm{C}\right)$, and $\Delta P$ is the pressure drop across the membrane (sheet).

\section{Results and Discussion}

The formation of a dense flow of $\mathrm{Al}\left(\mathrm{NO}_{3}\right)_{3} / \mathrm{PVP}$ precursor fibers in the AC-electrospinning process is presented in Figure 1. When an alternating electric field is applied to a layer of viscous polymer solution on the electrode surface (Fig.1a), it causes an instability that leads to the formation of a pulsating pattern of protrusions along the electrode's circumference during a few initial high voltage oscillations ( $20-80 \mathrm{~ms})$ (Fig.1b, insert). Next, the jets develop from those protrusions (Fig.1b) thus starting the fibrous flow (Fig1c). Once the jets are initiated, in the case of $\mathrm{Al}\left(\mathrm{NO}_{3}\right)_{3} / \mathrm{PVP}$ precursor the liquid layer quickly relaxes back to its initial shape, while multiple jets continue to generate randomly from the entire surface of the polymer solution quickly forming a fibrous cloud above the electrode surface (Fig.1d) accompanied by the charge recombination at its outer boundary. Next, the fibrous mass is pushed upwards by ionic wind [37,44], which results in a flow of solidified polymer fibers with a low residual electric charge (Fig.1e,f) propagating toward the collector located at $300-350 \mathrm{~mm}$ distance from the jet generating electrode (Fig.1g). The average speed of propagating flows of $\mathrm{Al}\left(\mathrm{NO}_{3}\right)_{3} / \mathrm{PVP}$ precursor fibers was in the range $0.2-0.4 \mathrm{~m} / \mathrm{s}$ and slightly dependent on the applied voltage.

It has been noted earlier that when spun from the same precursor, the results of the ACelectrospinning process can differ from those of other electrospinning methods [38,45]. Stable AC-electrospinning in the case of $\mathrm{Al}\left(\mathrm{NO}_{3}\right)_{3} / \mathrm{PVP}$ fibers was achieved with the precursor solution in ethanol containing up to $30 \mathrm{v} \%$ of water when the solution viscosity and electrical conductivity were in the range from 50 to $130 \mathrm{mPa} \cdot \mathrm{s}$ and from 10 to $14 \mu \mathrm{S}$, respectively. The 
precursor flow rates in present experiments were varied in the range from 15 to $40 \mathrm{~mL} / \mathrm{h}$ that allowed the fibrous mass collection rate up to $6.4 \mathrm{~g} / \mathrm{h}$. The representative SEM images of the precursor fibers with $\mathrm{Al}\left(\mathrm{NO}_{3}\right)_{3} / \mathrm{PVP}$ 1:1 weight ratio prepared at different AC-voltages are shown in Figure 2(a-c). Annealing of the precursor fibers in air at temperatures up to $1000{ }^{\circ} \mathrm{C}$ led to a drastic reduction in the volume and mass of the material while little changes were observed in the shape and surface morphology of fibers (Fig.2(b,c)).

It was observed that the diameter of $\mathrm{Al}\left(\mathrm{NO}_{3}\right)_{3} / \mathrm{PVP}$ precursor fibers decreases with the increase of AC-voltage. On average, the diameter reduced from $850 \pm 250 \mathrm{~nm}$ to $470 \pm 200 \mathrm{~nm}$ when the voltage changed from $19 \mathrm{kV}$ to $31 \mathrm{kV}$. The least spread of fiber diameters was achieved at $25-28 \mathrm{kV}$ rms AC-voltages. The diameters of fibers shrunk down to $200-300 \mathrm{~nm}$ after the annealing procedure. The observed trends in fiber diameters generated at different ACvoltages and calcined at 500, 700, and $1000{ }^{\circ} \mathrm{C}$ are summarized in Figure 3. Interestingly, there was statistically insignificant variation in the diameters of calcined fibers, although their initial diameters varied substantially depending on the AC-voltage. For example, the diameter of precursor fibers prepared at 19,25 , and $31 \mathrm{kV}$ reduced $2.5,1.7$ and 1.5 times, respectively, after the calcination at $500{ }^{\circ} \mathrm{C}$. One possible explanation of this fact is the voltage dependency of the organization of PVP molecules in the fiber that results in molecular stress in it. When the fiber is heated, the stress is relieved leading to fiber shrinkage. If the fibers prepared at higher voltage are more stressed along their axis, it is possible they shrink more along their length than radially. Thus, most of $\mathrm{Al}\left(\mathrm{NO}_{3}\right)_{3} / \mathrm{PVP}$ fiber shrinkage should occur at relatively low temperature before the polymer matrix starts to degrade. Once the polymer component is decomposed (below 500 ${ }^{\circ} \mathrm{C}$ ), further fiber shrinkage (1.1-1.4 times) at $700{ }^{\circ} \mathrm{C}$ and $1000{ }^{\circ} \mathrm{C}$ is associated with the crystallization and phase transformations of the inorganic component. 
FTIR spectroscopy (Figure 4a) revealed that the PVP spectrum changes a little in $\mathrm{Al}\left(\mathrm{NO}_{3}\right)_{3} / \mathrm{PVP}$ precursor nanofibers dried at $100-120{ }^{\circ} \mathrm{C}$ due to an overlap with aluminum nitrate absorption peaks at $\sim 1360 \mathrm{~cm}^{-1}\left(-\mathrm{NO}_{3}\right)$ and $1650 \mathrm{~cm}^{-1}(-\mathrm{OH})$ groups [46], and the all characteristic IR features of the precursor fibers disappear after calcination at $500{ }^{\circ} \mathrm{C}$. A broad asymmetric absorption band forms in the range from 500 to $1000 \mathrm{~cm}^{-1}$ at that temperature and it is associated with the formation of alumina. However, the material remained amorphous and did not produce any XRD pattern. A weak absorption band observed around $1500-1600 \mathrm{~cm}^{-1}$ is due to the carbonized residue. This band becomes weaker in the spectrum of $700{ }^{\circ} \mathrm{C}$ calcined material, and it completely disappears in the spectrum of $1000{ }^{\circ} \mathrm{C}$ calcined fibers. Both $700{ }^{\circ} \mathrm{C}$ and $1000{ }^{\circ} \mathrm{C}$ calcined alumina fibers show also a very weak but sharp $2340 \mathrm{~cm}^{-1}$ peak of $\mathrm{CO}_{2}$ adsorbed due to the increased micro-/mesoporosity in the calcined material as will be shown further in the text.

The broad absorption band in the range from 500 to $1000 \mathrm{~cm}^{-1}$ in $700{ }^{\circ} \mathrm{C}$ calcined nanofibrous alumina resembles the profile of such band reported for $\gamma$-alumina [47]. XRD pattern of this material shows three weak and broad maxima (Fig.4b) corresponding to (222), (400), and (440) reflections of $\gamma-\mathrm{Al}_{2} \mathrm{O}_{3}$ with the calculated crystallite size $6 \pm 1 \mathrm{~nm}$. The FTIR spectrum of the $1000{ }^{\circ} \mathrm{C}$ calcined sample indicates further evolution of Al-O absorption bands where the main band around $512 \mathrm{~cm}^{-1}$ can be fitted with two peaks centered at 544 and $486 \mathrm{~cm}^{-1}$. A small sharp peak can be noted at $728 \mathrm{~cm}^{-1}$ along with better defined broad absorption bands around 660 and $830 \mathrm{~cm}^{-1}$. These changes can be indicative to the formation of transitional alumina phases or $\alpha$-alumina $[28,48,49]$. The XRD pattern of $1000{ }^{\circ} \mathrm{C}$ calcined fibers is still dominated by the reflections of $\gamma$-alumina phase with the calculated crystallite size $11 \pm 1 \mathrm{~nm}$. A new peak at $2 \theta=25.5^{\circ}$ can be assigned to (012) reflection of $\alpha$-alumina phase with the calculated 
crystallite size $17 \pm 1 \mathrm{~nm}$, but other characteristic peaks of $\alpha$-alumina are absent. The formation of $\alpha-\mathrm{Al}_{2} \mathrm{O}_{3}$ has yet to be verified in this case, although the transition from $\gamma$ - to $\alpha$-alumina phase has been observed in $1000{ }^{\circ} \mathrm{C}$ calcined alumina fibers formed from various electrospun precursors $[28,32,34]$.

Figure 5 presents the results on the fabrication of nanofibrous alumina structures from the 25-kV rms AC-electrospun 1:1 $\mathrm{Al}\left(\mathrm{NO}_{3}\right)_{3} / \mathrm{PVP}$ precursor fiber sheets with 80-200 $\mu \mathrm{m}$ thickness (Fig.5a). Fibrous alumina constructs were formed from the multilayer assemblies of precursor fiber sheets (e.g., $75 \times 25 \mathrm{~mm}$ pieces and up 10 layers thick, Fig.5b) that were calcined at $700{ }^{\circ} \mathrm{C}$ (Fig.5c) and $1000{ }^{\circ} \mathrm{C}(\mathrm{d}, \mathrm{e})$, according to the procedure described in the experimental section. Visual and light microscopy examination indicated little warping and lack of cracking in the calcined structures. The nanofibrous sheets shrunk $2.4-2.8$ times after sintering at $700{ }^{\circ} \mathrm{C}$ for the lateral dimensions regardless the number of layers in the assembly. Concurrently, the thickness reduced typically $1.45-1.55$ and $2.4-2.5$ times for a single sheet and multilayer (7 sheets in this experiment) assembly, respectively. There was a little ( 10\%) further shrinkage in each direction observed after calcination at $1000{ }^{\circ} \mathrm{C}$. The corresponding volume shrinkage was as large as 1115 times and $18-25$ times after calcination at $1000{ }^{\circ} \mathrm{C}$ for the single nanofibrous alumina sheet and 7-sheet assembly, respectively.

In the used precursor fibrous material, nanofibers are packed mostly horizontally in a plane of individual sheet with a certain fraction of fibers present at the sheet surface (Fig.5f). These rather loose surface fibers have fewer contact points where they can clamp and fuse to each other during the compression and annealing, when compared to the bulk of the sheet. This can cause some anisotropy in the shrinking behavior of nanofibers across and along the fibrous sheet [45]. The role of loose surface fibers is therefore predicted to diminish in thicker or multilayer sheets 
that can lead to more uniform volume shrinkage and the formation of denser fibrous structures (Fig.5g). The observed shrinkage of the fibrous sheets correlates with the magnitude of changes in the dimensions of individual nanofibers (Fig.5h). The resulting apparent mass density of fibrous alumina sheets was $0.18-0.22 \mathrm{~g} / \mathrm{cm}^{3}$ and $0.26-0.28 \mathrm{~g} / \mathrm{cm}^{3}$ after calcination at $700{ }^{\circ} \mathrm{C}$ and $1000{ }^{\circ} \mathrm{C}$, respectively. It should be noted that the density of single nanofibrous alumina sheets was somewhat lower $(\sim 20 \%)$ than that of multilayer sheets. This was consistent with the difference in volume reduction of single sheet and multilayer assemblies during the calcination.

The analysis of nitrogen adsorption-desorption isotherms acquired for the $700{ }^{\circ} \mathrm{C}$ and 1000 ${ }^{\circ} \mathrm{C}$ calcined nanofibrous alumina sheets indicated the presence of both micro- and meso-pores in nanofibers. Some structural and textural characteristics of these materials are summarized in Table 1. Micropores were found as a dominating pore fraction (76.0\% of total pore volume) in the fibers calcined at $700{ }^{\circ} \mathrm{C}$, and mesopores dominated in fibers calcined at $1000{ }^{\circ} \mathrm{C}$ (micropore fraction was only $20.7 \%$ of total pore volume). Quite unexpectedly, the BET surface area was nearly the same in both materials. These numbers are 5-10 times lower than the magnitude of specific surface area usually reported for electrospun loose alumina nanofibers [27-29], but somewhat similar to that of electrospun commercial $\gamma$-alumina nanofibers as measured by Saunders et al [30] and $\gamma$-alumina membranes made from electrospun fibers [18]. The observed textural characteristics can possibly be associated with a denser fiber structure achieved due to the selected calcination procedure and the composition of the precursor fibers. It has been suggested that the fibers calcined at $700{ }^{\circ} \mathrm{C}$ could contain closed micropores that do not contribute to the measured numbers of the surface area and micropore volume. Furthermore, the fiber-to-fiber interaction due to the precursor fiber bundling in the propagating fibrous flow during the AC-electrospinning and additional fiber clamping during the sheet compression can 
contribute towards the reduction of the surface area. The fibers densify further during the calcination at $1000{ }^{\circ} \mathrm{C}$ and exhibit the grain growth. The volume of open and closed micropores declines through the formation of more mesopores, which leads to a much larger total pore volume while keeping the specific surface area nearly the same.

Air permeability (Darcy's permeability parameter $\left.k_{D}\right)$ and apparent air flow resistance $\left(R_{D}\right)$ were determined for several nanofibrous alumina single sheets and multilayer assemblies in order to evaluate their potential for the fabrication of filtration membranes and for other related applications. The results of these preliminary experiments are summarized in Fig.6. The numbers for Darcy's permeability parameter were found within $(1.5-3.0) \times 10^{-13} \mathrm{~m}^{2}$ for all tested nanofibrous structures with the membrane diameter of $5 \mathrm{~mm}$, their thicknesses in the range from 40 to $360 \mu \mathrm{m}$, and calcined between $500{ }^{\circ} \mathrm{C}$ and $1000{ }^{\circ} \mathrm{C}$. These numbers are comparable, on one hand, with the $k_{D}$ reported for extruded porous alumina ceramics with unidirectionally aligned pores $(10-40 \mu \mathrm{m}$ pore size and $>40 \%$ porosity) [42]. On the other hand, Fernando and Chung [41] reported 2-20 times larger $k_{D}$ numbers for the fibrous membranes with the apparent mass density of $0.255 \mathrm{~g} / \mathrm{cm}^{3}$ and composed of $3-\mu \mathrm{m}$ diameter alumina fibers, whereas Wiheeb et al [50] measured 2-4 times lower $k_{D}$ for the membranes composed of a 9- $\mu$ m mesoporous $\gamma$ alumina layer calcined at $600{ }^{\circ} \mathrm{C}$ on a macroporous $\alpha$-alumina support sintered from powder at $1000{ }^{\circ} \mathrm{C}$.

The observed initial decrease in the measured $k_{D}$ magnitudes with the increase in pressure drop (Fig.6a) across all tested nanofibrous alumina membranes can occur due to a partial compression of the membrane [51] and macropore closure. Once a steady state was reached, the permeability of $700{ }^{\circ} \mathrm{C}$ and $1000{ }^{\circ} \mathrm{C}$ calcined membranes remained nearly constant until the membrane failed. A few kinks were observed in the permeability graphs of multilayer 
membranes. These kinks can occur as the result of sudden membrane deformation due to the relative sliding displacement of individual layers in the multilayer assembly, which could lead to macropore opening or closure. Such kinks were not observed in the single-sheet membranes, and it is not clear if they occur in $500{ }^{\circ} \mathrm{C}$ calcined multilayer assembly.

An increase in permeability above $\Delta P=10 \mathrm{kPa}$ for the multilayer fibrous membrane calcined at $500{ }^{\circ} \mathrm{C}$ has been assigned to the membrane's partial stretching and increase of the distance between the fibers due to assumingly higher elasticity of this material. The shape of this membrane after the failure (photo in Fig.6b) is consistent with the deformation of rather elastic fabric membranes [52]. The $500{ }^{\circ} \mathrm{C}$ calcined fibrous alumina membranes possessed also the lowest permeability and largest air flow resistance among the other tested structures. Both 700 ${ }^{\circ} \mathrm{C}$ and $1000{ }^{\circ} \mathrm{C}$ calcined single fibrous sheet membranes showed the same behavior of permeability and air flow resistance, as well as rather similar brittle failure features (Fig.6b). Similar trends were also observed for the multilayer membranes. The lower $k_{D}$ of $1000{ }^{\circ} \mathrm{C}$ calcined membranes was assigned to their denser structure when compared to $700{ }^{\circ} \mathrm{C}$ calcined ones $\left(0.275 \mathrm{~g} / \mathrm{cm}^{3}\right.$ vs $\left.0.220 \mathrm{~g} / \mathrm{cm}^{3}\right)$. The $700{ }^{\circ} \mathrm{C}$ calcined $360 \mu \mathrm{m}$ thick material had the best overall performance (permeability $2.77 \times 10^{-13} \mathrm{~m}^{2}$ (or $0.28 \mathrm{Darcy}$ ), $\Delta P=47 \mathrm{kPa}$ at failure).

\section{Conclusions}

Nanocrystalline alumina $\left(\mathrm{Al}_{2} \mathrm{O}_{3}\right)$ nanofibers, derived from 1:1 $\mathrm{Al}\left(\mathrm{NO}_{3}\right)_{3} / \mathrm{PVP}$ precursor fibers collected at the rates up to $6.4 \mathrm{~g} / \mathrm{h}$ using a free-surface AC-electrospinning, exhibit the fiber diameter, surface morphology, and structure that to a certain extent are characteristic to alumina fibers produced from various precursors by other electrospinning methods. The 
formation of dense weakly charged fiber flows in AC-electrospinning method provides a capability for easier fiber handling and better fiber collection schemes.

AC-electrospun 100-300 $\mu \mathrm{m}$ thick single nanofibrous sheets and their multilayer assemblies were prepared and converted into nanofibrous $\gamma$-alumina structures using the calcination temperatures between 700 and $1000{ }^{\circ} \mathrm{C}$. The initial volume of calcined nanofibrous alumina single sheets shrunk 11-15 times, but little deformation and cracking was observed. Such volume shrinkage of fibrous structures appears to be proportional to that of individual nanofibers. However, the fiber shrinkage in radial and axial directions can be non-uniform due to the stress in precursor fibers determined by the voltage dependency of the organization of polymer molecules. Volume shrinkage of multilayer assemblies was 18-25 times, mostly due to the thickness reduction. Significant fiber bundling noted in AC-electrospinning, fiber collection procedure, inter-fiber interactions within the single sheet and multilayer fibrous assemblies during the compression, and the peculiarities of fiber shrinkage during calcination can define the final size, microarchitecture, and micro-/mesoporosity of the final structure, as well as its mechanical properties.

Air permeability and apparent air flow resistance parameters with the single sheet and multilayer nanofibrous alumina membranes were found comparable with porous alumina membranes of various designs and fabricated by different methods. This allows the nanofibrous alumina structures derived from AC-electrospun precursor fibers to be considered as a candidate material suitable for gas filtration and separation membranes, and other applications. The possibility of slipping between the layers in multilayer nanofibrous sheet assemblies and its effect on the mechanical properties and function of the structures are yet to be explored. 


\section{Acknowledgements}

This work was supported by the National Science Foundation International Research Experience for Students (IRES) Grant \#1261154 and by the Project OP VaVpI Centre for Nanomaterials, Advanced Technologies and Innovation CZ.1.05/2.1.00/01.0005. The authors thank Jerry Sewell for making many critical parts and components of the AC-electrospinning system, and Jonghwa Oh for the help with textural properties analysis.

\section{References}

[1] M.C. Almandoz, C.L. Pagliero, N.A. Ochoa, J. Marchese, Composite ceramic membranes from natural aluminosilicates for microfiltration applications, Ceram. Int. 41 (2015) 5621-5633.

[2] M. Raja, N. Angulakshmi, S. Thomas, T.P. Kumar, A.M. Stephan, Thin, flexible and thermally stable ceramic membranes as separator for lithium-ion batteries, J. Membrane Sci. 471 (2014) 103-109.

[3] R. Goei, T.T. Lim, Asymmetric $\mathrm{TiO}_{2}$ hybrid photocatalytic ceramic membrane with porosity gradient: Effect of structure directing agent on the resulting membranes architecture and performances, Ceram. Int. 40 (2014) 6747-6757.

[4] J. Kujawa, S. Cerneaux, W. Kujawski, Removal of hazardous volatile organic compounds from water by vacuum pervaporation with hydrophobic ceramic membranes, J. Membrane Sci. 474 (2015) 11-19.

[5] D. Mancinelli, C. Hallé, Nano-filtration and ultra-filtration ceramic membranes for food processing: A mini review. J. Membrane Sci. Technol. 5 (2015) 140 (13 pages).

[6] X.B. Ke, H.Y. Zhu, X.P. Gao, J.W. Liu, Z.F. Zheng, High-performance ceramic membranes with a separation layer of metal oxide nanofibers, Adv. Mater. 19 (2007) 785-790. 
[7] Y. Dai, W. Liu, E. Formo, Y. Sun, Y. Xia, Ceramic nanofibers fabricated by electrospinning and their applications in catalysis, environmental science, and energy technology, Polym. Adv. Technol. 22 (2001) 326-338.

[8] D. Malwal, P. Gopinath, Fabrication and applications of ceramic nanofibers in water remediation: A review, Critical Rev. Environ. Sci. Technol. 46 (2016) 500-534

[9] M. Büyükyazi, S. Mathur, 3D nanoarchitectures of $\alpha-\mathrm{LiFeO}_{2}$ and $\alpha-\mathrm{LiFeO}_{2} / \mathrm{C}$ nanofibers for high power lithium-ion batteries, Nano Energy 13 (2015) 28-35.

[10] A. Nikfarjam, N. Salehifar, Improvement in gas-sensing properties of $\mathrm{TiO}_{2}$ nanofiber sensor by UV irradiation, Sensors and Actuators B: Chem. 211 (2015) 146-156.

[11] A. Sedaghat, E. Taheri-Nassaj, R. Naghizadeh, An alumina mat with a nano microstructure prepared by centrifugal spinning method, J. Non-Cryst. Solids 352 (2006) 2818-2828.

[12] A. Biswas, H. Park, W.M. Sigmund, Flexible ceramic nanofiber mat electrospun from $\mathrm{TiO}_{2^{-}}$ $\mathrm{SiO}_{2}$ aqueous sol, Ceram. Int. 38 (2012) 883-886.

[13] Y. Si, X. Mao, H. Zheng, J. Yu, B. Ding, Silica nanofibrous membranes with ultra-softness and enhanced tensile strength for thermal insulation, RSC Adv. 5 (2015) 6027-6032.

[14] L. Ren, R. Ozisik, S.P. Kotha, Rapid and efficient fabrication of multilevel structured silica micro-/nanofibers by centrifugal jet spinning, J. Colloid Interface Sci. 425 (2014) 136-142.

[15] E. Formo, M.S. Yavuz, E.P. Lee, L. Lane, Y. Xia, Functionalization of electrospun ceramic nanofiber membranes with noble-metal nanostructures for catalytic applications, J. Mater. Chem. 19 (2009) 3878-3882.

[16] V. Su, M. Terehov, B. Clyne, Filtration Performance of Membranes Produced Using Nanoscale Alumina Fibers (NAF), Adv. Eng. Mater. 14 (2012) 1088-1096. 
[17] M. Vahtrus, M. Umalas, B. Polyakov, L. Dorogin, R. Saar, M. Tamme, K. Saal, R. Lõhmus, S. Vlassov, Mechanical and structural characterizations of gamma- and alpha-alumina nanofibers, Mater. Charact. 107 (2015) 119-124.

[18] Y. Wang, W. Li, Y. Xia, X. Jiao, D. Chen, Electrospun flexible self-standing $\gamma$-alumina fibrous membranes and their potential as high-efficiency fine particulate filtration media, J. Mater. Chem. A 2 (2014) 15124-15131.

[19] A.M. Azad, Fabrication of transparent alumina $\left(\mathrm{Al}_{2} \mathrm{O}_{3}\right)$ nanofibers by electrospinning, Mater. Sci. Eng. A 435-436 (2006) 468-473.

[20] D. Lai, Y. Chen, D. Yang, W. Guo, Y. Yu, Alumina $\left(\mathrm{Al}_{2} \mathrm{O}_{3}\right)$ nanofibers from electrospinning, Adv. Mater. Res. 476-478 (2012) 379-382.

[21] W. Kang, B. Cheng, Q. Li, X. Zhuang, Y. Ren, A new method for preparing alumina nanofibers by electrospinning technology, Textile Res. J. 81 (2011) 148-155.

[22] P.K. Panda, S. Ramakrishna, Electrospinning of alumina nanofibers using different precursors, J. Mater. Sci. 42 (2007) 2189-2193.

[23] E. Carneiro, P. Sá, B. Almeida, C.A. Pinto, J.T. Fernandes, J.P. Mendonça, S. Carvalho, Effect of electrospun alumina nanofibers incorporation in ceramic glaze, J. Ceram. Sci. Technol. $6(2015)$ 69-74.

[24] P.C. Yu, R.J. Yang, Y.Y. Tsai, W. Sigmund, F.S. Yen, Growth mechanism of single-crystal $\alpha-\mathrm{Al}_{2} \mathrm{O}_{3}$ nanofibers fabricated by electrospinning techniques, J. Eur. Ceram. Soc. 31 (2011) 723731.

[25] M.M. Dimitrova, E.D. Krumov, D.B. Karashanova, Simplified procedure for $\mathrm{Al}_{2} \mathrm{O}_{3}$ microfibers preparation by the method of electrospinning, Bulgarian Chem. Comm. 45 (Spec. Issue B) (2013) 94-98. 
[26] S. Zhang, X.Y. Cao, Y.M. Ma, Fabrication of alumina ribbons with mixed solvent system in electrospinning, J. Optoel. Adv. Mater. 13 (2011) 425-427.

[27] Y.Wang, W. Li, X. Jiao, D. Chen, Electrospinning preparation and adsorption properties of mesoporous alumina fibers, J. Mater. Chem. A 1 (2013) 10720-10726.

[28] J.H. Kim, S.J. Yoo, D.H. Kwak, H.J. Jung, T.Y. Kim, K.H. Park, J.W. Lee, Characterization and application of electrospun alumina nanofibers, Nanoscale Res. Lett. 9 (2014) 44-49.

[29] A. Mahapatra, B.G. Mishra, G. Hota, Synthesis of ultra-fine $\alpha-\mathrm{Al}_{2} \mathrm{O}_{3}$ fibers via electrospinning method, Ceram. Int. 37 (2011) 2329-2333.

[30] Z. Saunders, C.W. Noack, D.A. Dzombak, G.V. Lowry, Characterization of engineered alumina nanofibers and their colloidal properties in water, J. Nanoparticle Res. 17 (2015) 140153.

[31] Z. Zhao, X. Shen, H. Yao, J. Wang, J. Chen, Z. Li, Alumina nanofibers obtained via electrospinning of pseudo-boehmite sol/PVP solution, J. Sol-Gel Sci. Technol. 70 (2014) 72-80.

[32] X. Tang, Y. Yu, Electrospinning preparation and characterization of alumina nanofibers with high aspect ratio, Ceram. Int. 41 (2015) 9232-9238.

[33] P. Milanović, M. Dimitrijević, R. Jančić Heinemann, J. Rogan, D.B. Stojanović, A. Kojović, R. Aleksić, Preparation of low cost alumina nanofibers via electrospinning of aluminium chloride hydroxide/poly (vinyl alcohol) solution, Ceram. Int. 39 (2013) 2131-2134.

[34] P. Liu, Y. Zhu, J. Ma, S. Yang, J. Gong, J. Xu, Preparation of continuous porous alumina nanofibers with hollow structure by single capillary electrospinning, Colloids and Surf. A: Physicochem. Eng. Aspects 436 (2013) 489-494.

[35] R. Kessick, J. Fenn, G. Tepper, The use of AC potentials in electrospraying and electrospinning processes, Polymer 45 (2004) 2981-2984. 
[36] S. Maheshwari, H.C. Chang, Assembly of multi-stranded nanofiber threads through AC electrospinning, Adv. Mater. 21 (2009) 349-354.

[37] P. Pokorny, E. Koštáková, F. Sanetmik, P. Mikes, J. Chvojka, T. Kalous, M. Bilek, K. Pejchar, J. Valtera, D. Lukaš, Phys. Chem. Chem. Phys. 16 (2014) 26816-26822.

[38] C. Lawson, A. Stanishevsky, M. Sivan, P. Pokorny, D. Lukáš, Rapid fabrication of poly( $\varepsilon^{-}$ caprolactone) fibers using needleless alternating current electrospinning, J. Appl. Polymer Sci. 133 (2016) 43232.

[39] ICDD, S. Kabekkodu, Ed., Powder Diffraction File 2007.

[40] B. D. Cullity, Elements of XRD, Addison-Wesley, Reading, MA, USA, $2^{\text {nd }}$ edition, 1978.

[41] J.A. Fernando, D.D.L. Chung, Pore structure and permeability of an alumina fiber filter membrane for hot gas filtration, J. Porous Mater. 9 (2002) 211-219.

[42] T. Isobe, Y. Kameshima, A. Nakajima, K. Okada, Y. Hotta, Gas permeability and mechanical properties of porous alumina ceramics with unidirectionally aligned pores, J. Eur. Ceram. Soc. 27 (2007) 53-59.

[43] F. Dullien, Porous media - fluid transport and pore structure, Academic Press, New York, 1979, p. 157.

[44] A.M. Drews, L.Cademartiri, G.M. Whitesides, K.J.M. Bishop, J.Appl. Phys. 114 (2012) 143302.

[45] A. Stanishevsky, J. Wetuski, M. Walock, I. Stanishevskaya, H. Yockell-Lelièvre, E. Koštáková, D. Lukaš, Ribbon-like structures of tungsten oxide nanofibers fabricated via electrospinning, RCS Advances 5 (2015) 69534-69542.

[46] B. Pacewska, M. Keshr, Thermal transformations of aluminium nitrate hydrate, Thermochimica Acta 385 (2002) 73-80. 
[47] J.M. Saniger, Al-O infrared vibrational frequencies of $\gamma$-alumina, Mater. Lett 22 (1995) 109-113.

[48] S.Y. Reyes-López, R.S. Acuña, R. López-Juárez, J.S. Rodríguez, Analysis of the phase transformation of aluminum formate $\mathrm{Al}_{(}\left(\mathrm{O}_{2} \mathrm{CH}\right)_{3}$ to $\alpha$-alumina by Raman and infrared spectroscopy, J. Ceram. Proc. Res. 14, (2013) 627-631.

[49] L. Favaro, A. Boumaza, P. Roy, J. Lédion, G. Sattonnay, J.B. Brubach, A.M. Huntz, R. Tétot, Experimental and ab initio infrared study of $\chi-, \kappa$ - and $\alpha$-aluminas formed from gibbsite, $\mathrm{J}$. Solid State Chem. 183 (2010) 901-908.

[50] A.D. Wiheeb, M.A. Ahmad, M.N. Murat, J. Kim, M.R. Othman, Identification of molecular transport mechanisms in micro-porous hydrotalcite-silica membrane, Transp. Porous Med. 104 (2014) 133-144.

[51] L.T. Choong, Z. Khan, G.C. Rutledge, Permeability of electrospun fiber mats under hydraulic flow, J. Membrane Sci. 451 (2014) 111-116.

[52] P.W. Gibson, K. Desabrais, T. Godfrey, Dynamic permeability of porous elastic fabrics, J. Eng. Fibers and Fabrics 7, Special Issue (2012) 29-36. 


\section{Figure Captions}

Figure 1. (a) Process schematics: the precursor solution is supplied through a hollow electrode 1 that is connected to a grounded high-voltage transformer 2 through a current-limiting resistor 3; Electrified jets are generated from a layer of precursor and form a flow of fibers 4 that are deposited on a rotating plastic collector 5; (b) High-speed video shots (2000 fps) of a layer of precursor solution on the 8-mm diameter electrode at the jet initiation (insert) and development stage; (c) close up photo (12 mm diameter electrode) of the polymer jets emitting from $\mathrm{Al}\left(\mathrm{NO}_{3}\right)_{3} / \mathrm{PVP}$ precursor during the $\mathrm{AC}$-electrospinning at $25 \mathrm{kV}$ rms voltage; (d-gf) various stages in the development of the fibrous flow propagating towards a rotating collector.

Figure 2. Representative SEM images of $\mathrm{AC}$-electrospun (a-c) precursor $\mathrm{Al}\left(\mathrm{NO}_{3}\right)_{3} / \mathrm{PVP}$ fibers, and (d-f) fibers after the annealing for $2 \mathrm{~h}$ at $1000{ }^{\circ} \mathrm{C}$.

Figure 3. The effect of $\mathrm{AC}$ voltage on the diameter of the $\mathrm{Al}\left(\mathrm{NO}_{3}\right)_{3} / \mathrm{PVP}$ precursor and annealed alumina fibers.

Figure 4. (a) FTIR spectra of the precursor $\mathrm{Al}\left(\mathrm{NO}_{3}\right)_{3} / \mathrm{PVP}$ and calcined alumina fibers, and (b) XRD patterns of crystallized fibers sintered at $700{ }^{\circ} \mathrm{C}$ and $1000{ }^{\circ} \mathrm{C}$.

Figure 5. Fabrication of fibrous alumina constructs: (a) as prepared $\sim 300 \mathrm{~mm} \times 210 \mathrm{~mm}$ sheet, (b) multi-sheet assembly of $\mathrm{Al}\left(\mathrm{NO}_{3}\right)_{3} / \mathrm{PVP}$ precursor nanofibers, and multi-sheet alumina constructs sintered at (c) $700{ }^{\circ} \mathrm{C}$ and (d,e) $1000{ }^{\circ} \mathrm{C}$; SEM images of sintered at $1000{ }^{\circ} \mathrm{C}$ (f) noncompressed and (g) compressed fibrous alumina single sheet, and (h) individual alumina nanofibers.

Figure 6. Darcy's (a) permeability and (b) apparent air flow resistance of nanofibrous alumina sheets with different thickness calcined at 500, 700, and $1000{ }^{\circ} \mathrm{C}$. 
Table 1. Structural and textural characteristics of nanofibrous alumina sheets sintered at $700{ }^{\circ} \mathrm{C}$ and $1000{ }^{\circ} \mathrm{C}$ :

\begin{tabular}{|c|c|c|c|c|c|c|c|c|}
\hline Sample & $\begin{array}{c}\text { Fiber } \\
\text { diameter, } \\
\mathrm{nm}\end{array}$ & $\begin{array}{c}\text { Grain } \\
\text { size, } \\
\mathrm{nm}\end{array}$ & $\begin{array}{c}\text { Apparent } \\
\text { mass } \\
\text { density, } \\
\mathrm{g} / \mathrm{cm}^{3}\end{array}$ & $\begin{array}{c}\text { BET } \\
\text { surface } \\
\text { area, } \\
\mathrm{m}^{2} / \mathrm{g}\end{array}$ & $\begin{array}{c}\text { Total } \\
\text { pore } \\
\text { volume, } \\
\mathrm{cm}^{3} / \mathrm{g}\end{array}$ & $\begin{array}{c}\text { t-plot } \\
\text { micropore } \\
\text { volume, } \\
\mathrm{m}^{3} / \mathrm{g}\end{array}$ & $\begin{array}{c}\mathrm{BET}_{(4 \mathrm{~V} / \mathrm{A})} \\
\text { pore } \\
\text { width, } \\
\mathrm{nm}\end{array}$ & $\begin{array}{c}\text { BJH ads. / } \\
\text { desorp. pore } \\
\text { diameter, } \\
\mathrm{nm}\end{array}$ \\
\hline $700^{\circ} \mathrm{C}$ & $267 \pm 85$ & $6.0 \pm 1.0$ & 0.200 & 13.6 & 0.0075 & 0.0057 & 2.20 & $27.4 / 13.9$ \\
\hline $1000^{\circ} \mathrm{C}$ & $256 \pm 95$ & $14.0 \pm 3.0$ & 0.275 & 14.7 & 0.0237 & 0.0049 & 6.45 & $17.1 / 6.9$ \\
\hline
\end{tabular}




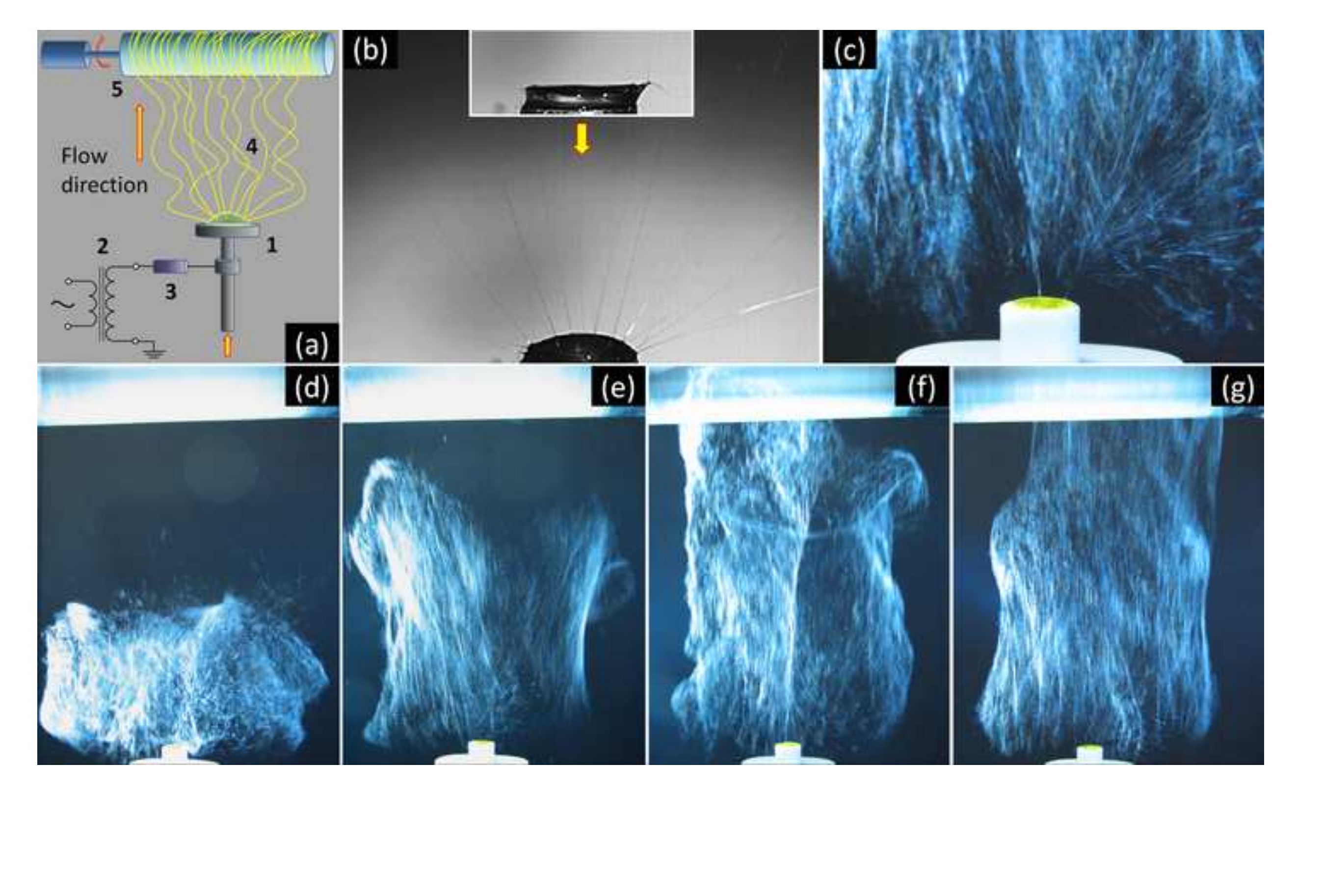

Figures

.

Figure

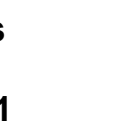

.

.
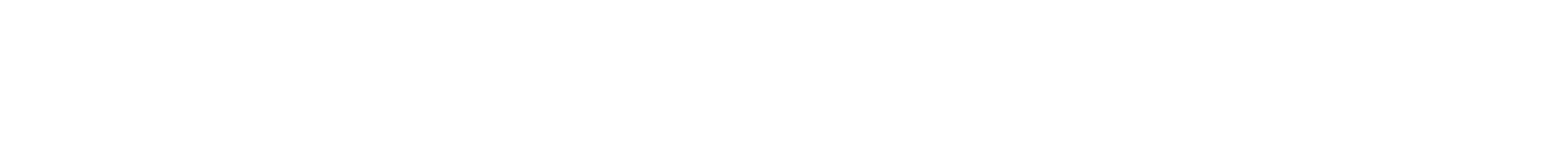
)
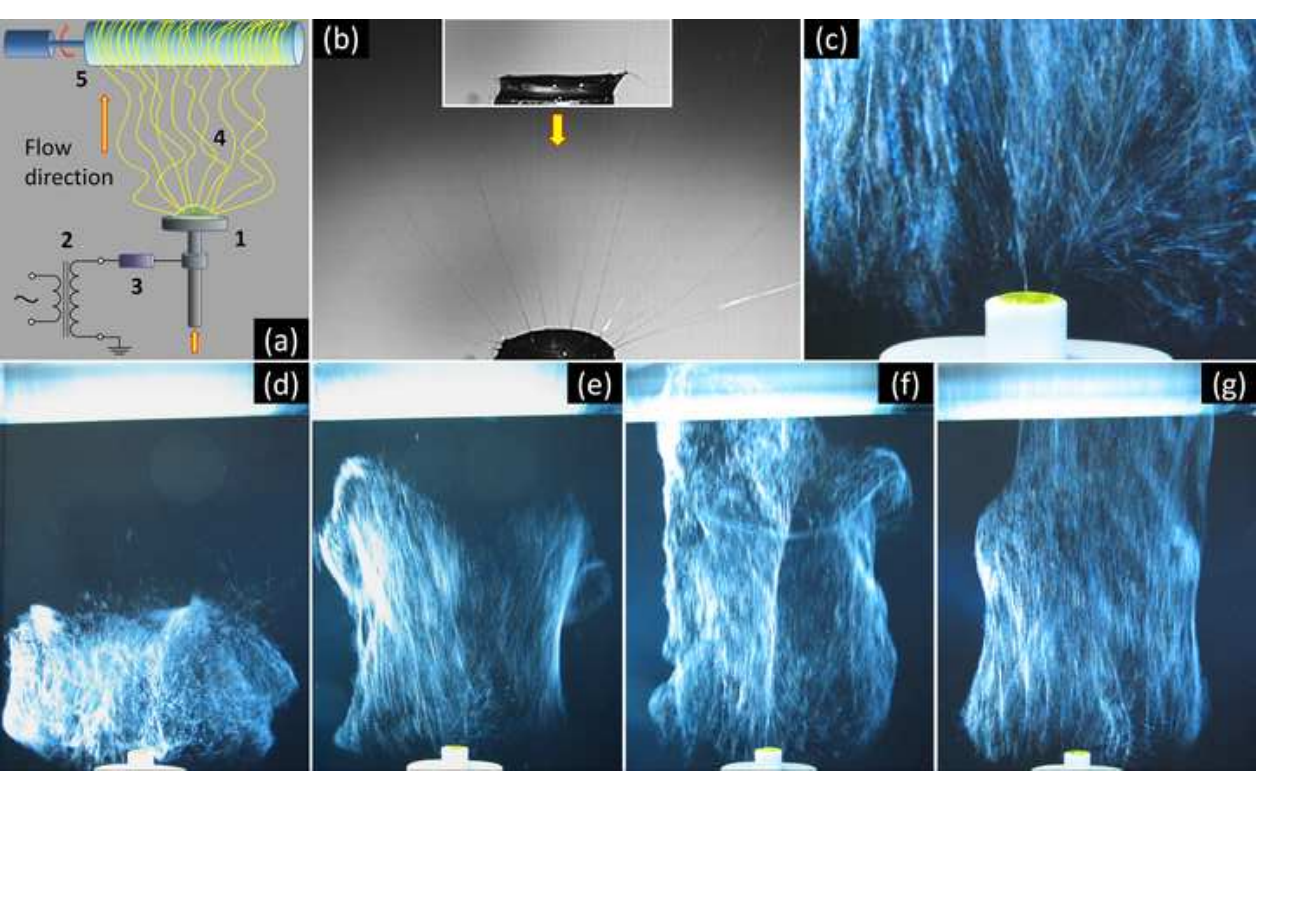


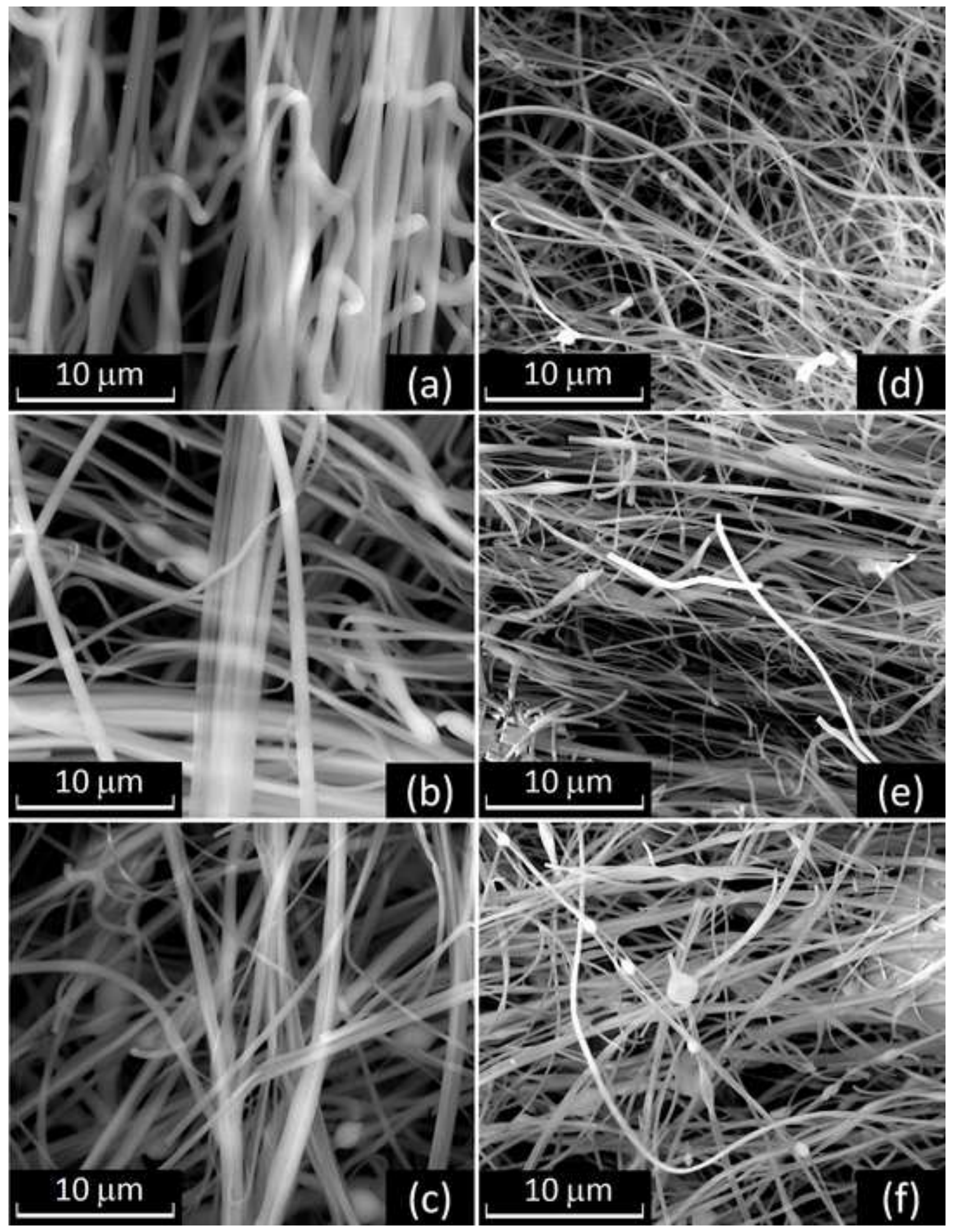




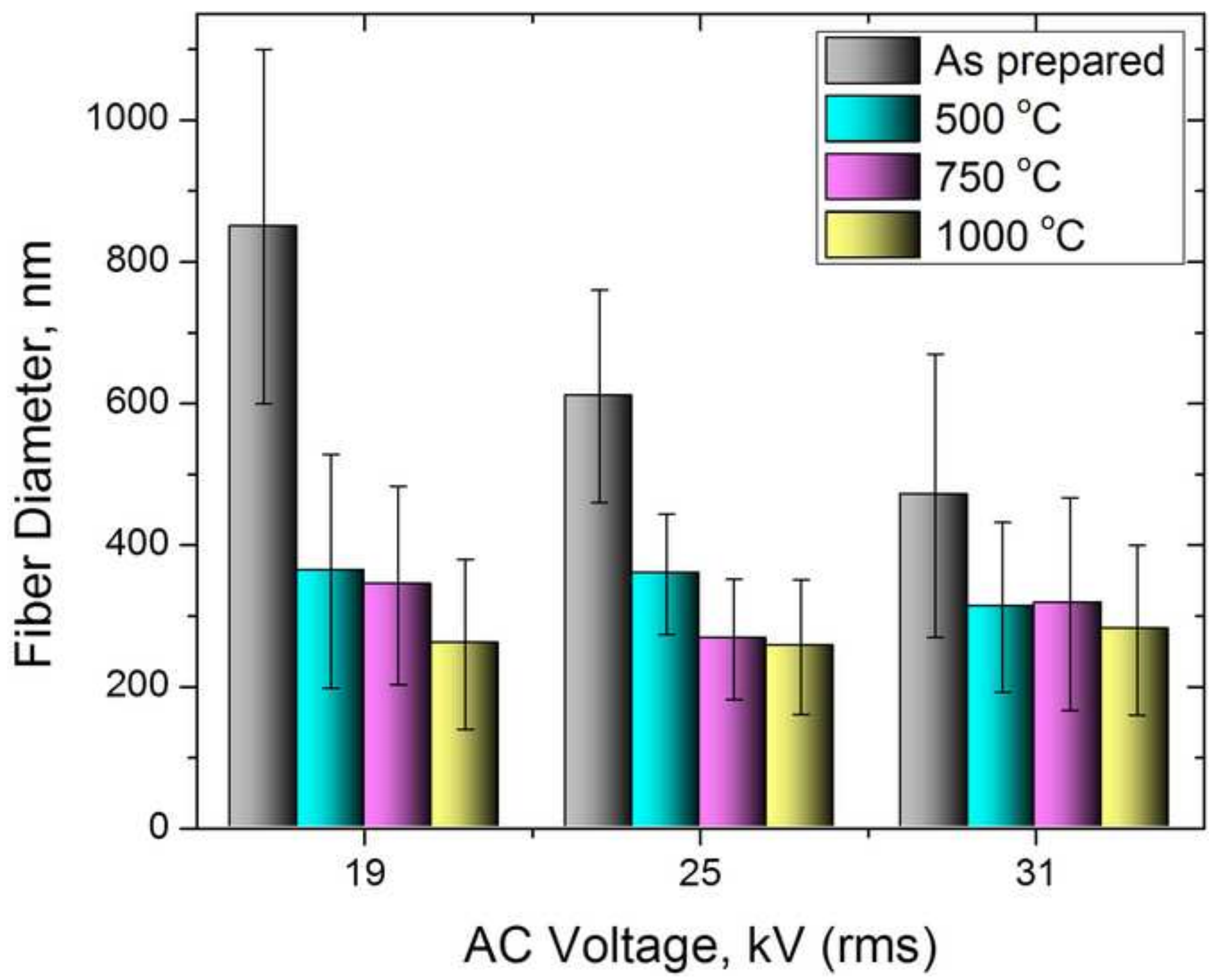



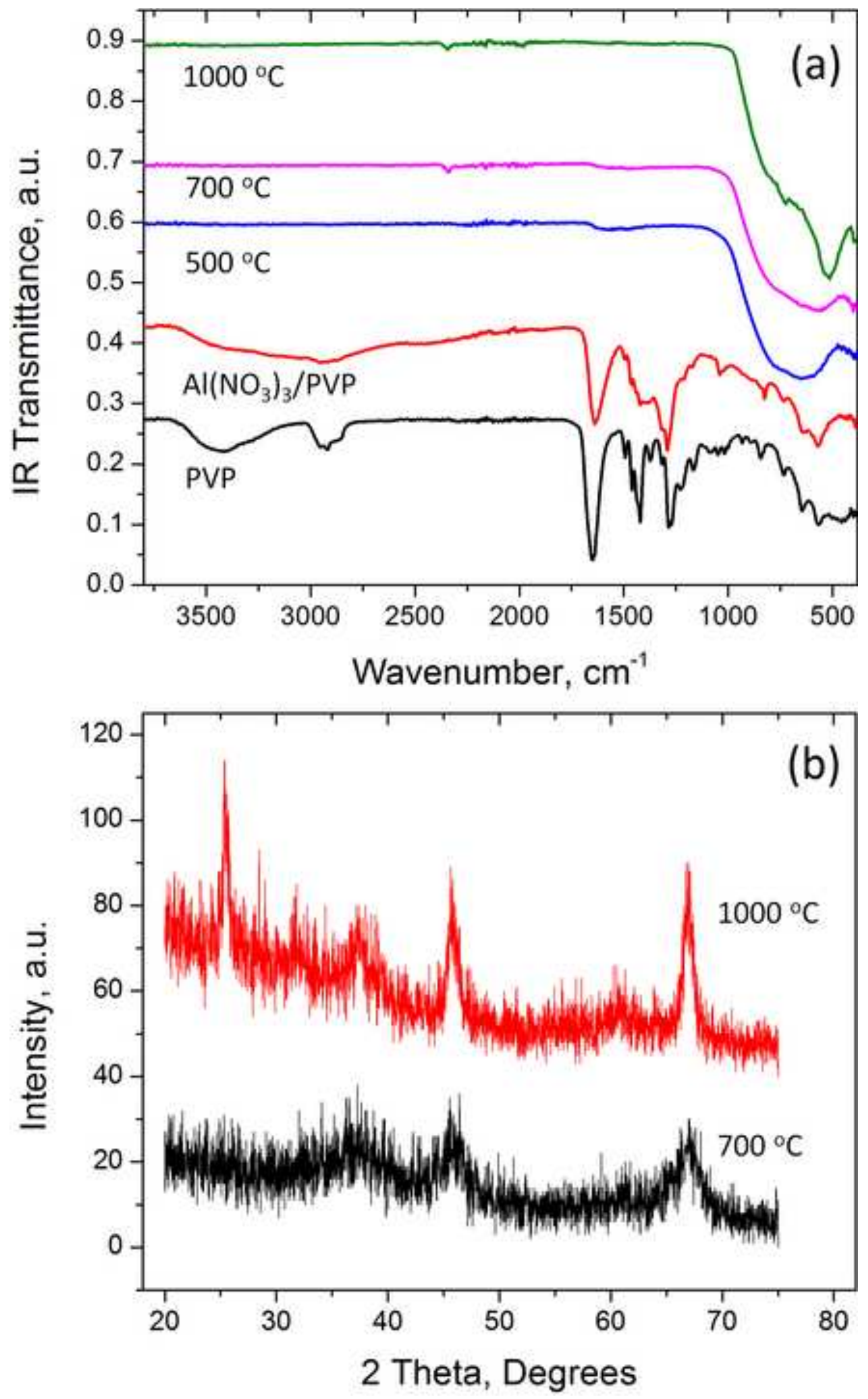

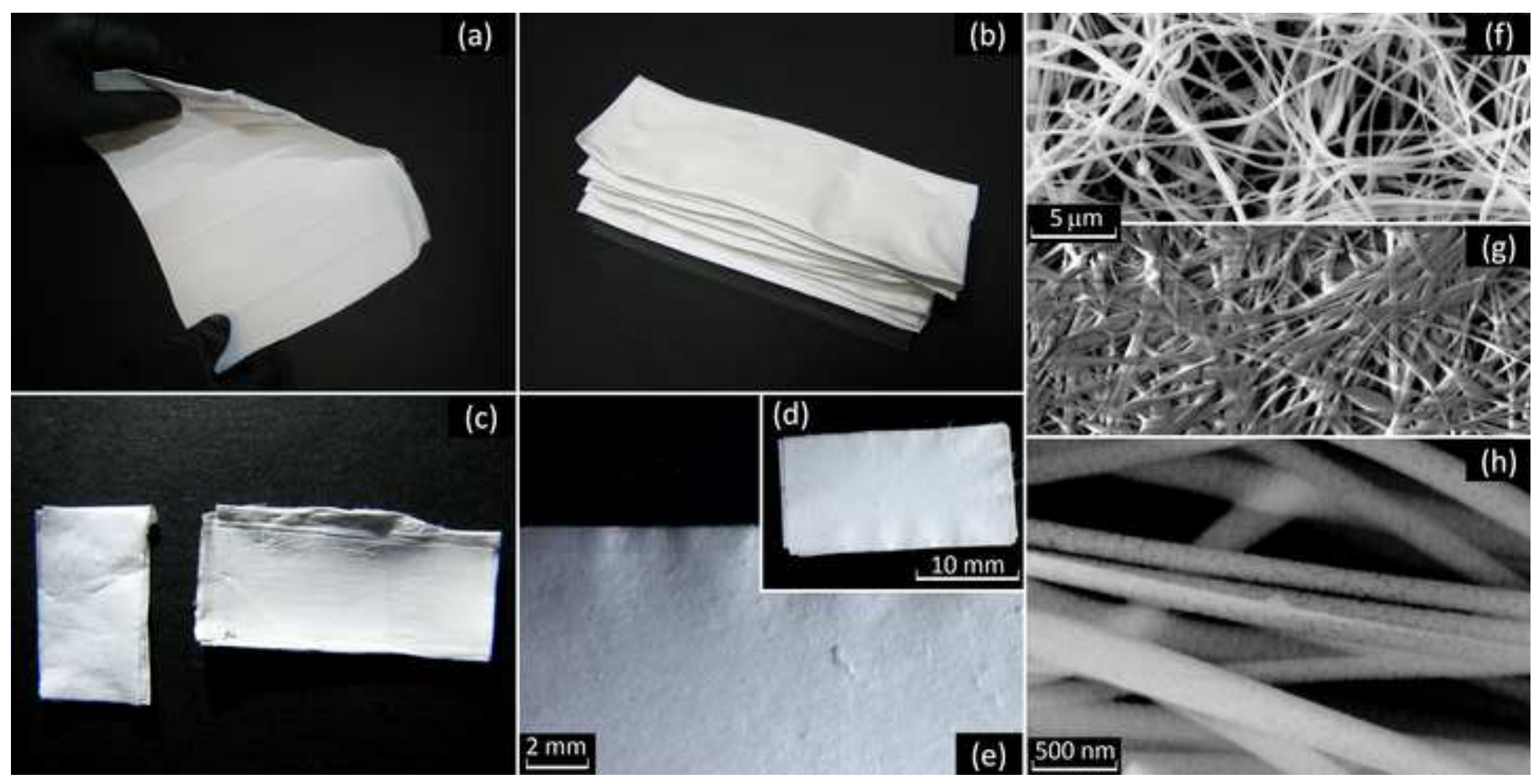

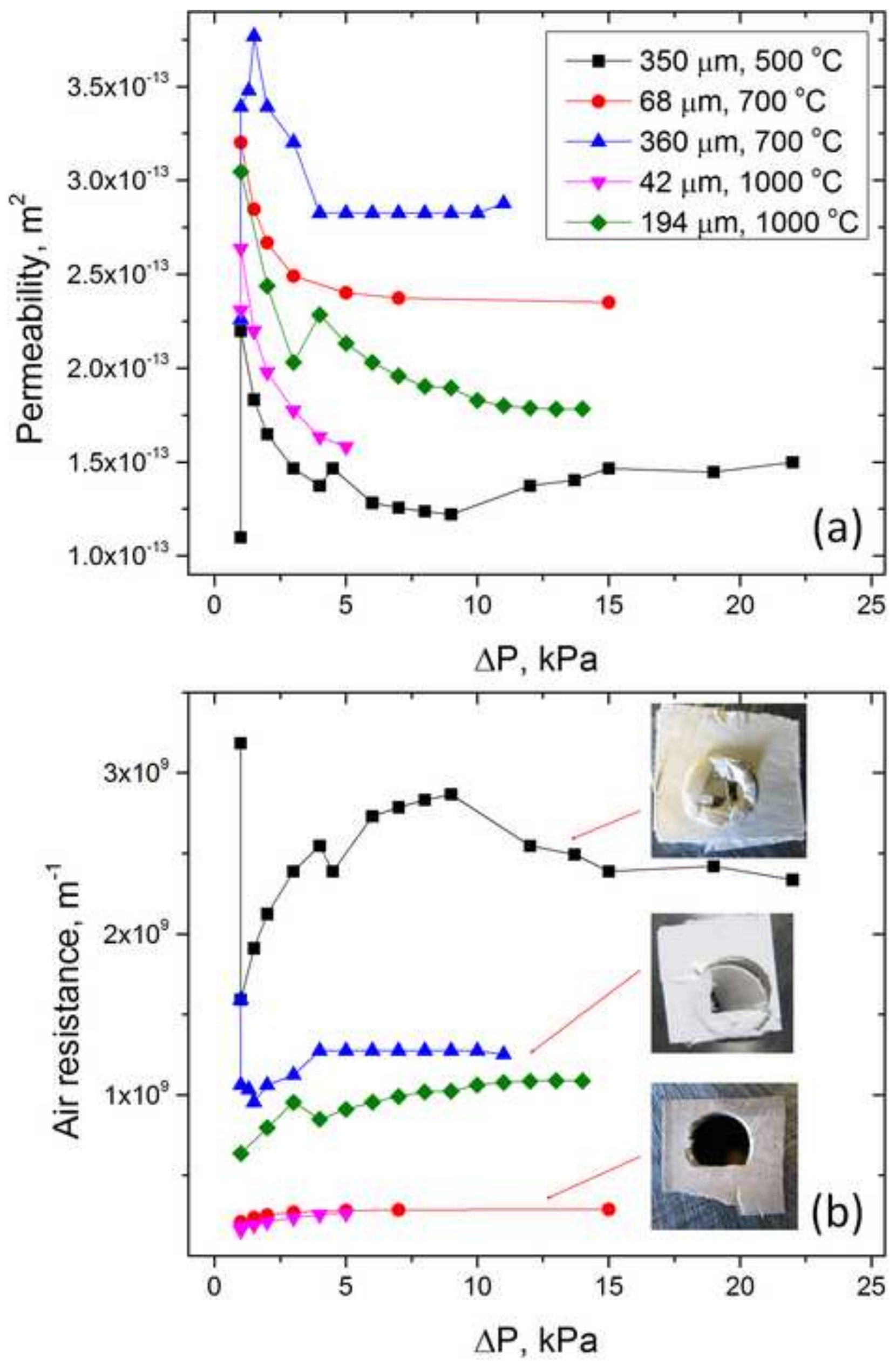